\title{
TRANSCRIPTION FACTORS AND AGING
}

\author{
Arun K. Roy \\ Department of Cellular and Structural Biology, The University of \\ Texas Health Science Center at San Antonio, San Antonio, \\ Texas, U.S.A.
}

The biology of aging is still an emerging field and, as such, is replete with controversies and contradictions. The purpose of this short review is to highlight literature leading in a general direction; it is not intended to be either comprehensive or inclusive of diverse points of view. Although the definition of aging itself is controversial, in the case of higher animals, it can be defined as a progressive deterioration of biological functions observed only after the organism has attained its maximum reproductive competence (1). Such age-dependent decline of biological functions involves complex interactions among many contributing factors. However, the sequentially activated genetic programs resulting in the accumulation of biochemical damages appear to play the most dominant role. Thus, the temporally programmed expression of certain genes with key regulatory functions may serve as the major determinant for the species-specific differences in the rate of aging and the maximum life-span potential of the organism (1-4).

Contrary to popular opinion, aging is not an inevitable consequence of the living process itself. Rather, it is an evolutionarily acquired phenomenon $(5,6)$. Even primitive organisms have developed a highly efficient enzymatic machinery for repairing the damages that occur during day-to-day living (7). Additionally, in multicellular organisms, any grossly damaged cell can be eliminated through programmed cell death (apoptosis) (8). The high degree of efficiency of these two corrective processes is indicated by the fact that in higher animals the time-dependent

Address correspondence and reprint requests to: Dr. Arun K. Roy, Department of Cellular and Structural Biology, The University of Texas Health Science Center at San Antonio, San Antonio, TX 78284, U.S.A. Phone: 210-567-3850; fax: 210-567-3846; e-mail: roy@uthscsa.edu decline of physiological functions is held off until the attainment of maximum reproductive competence. Even at the cellular level, abeyance of such time-dependent damages for a prolonged period is exemplified by the observation that in certain insects such as bees and ants, after a single mating, viable and fertile sperm cells are maintained in the spermatheca of the queen for the rest of her life, which can be as long as 10-15 years (9). However, because of the high energetic demand of these corrective processes, the maintenance of unimpaired biological functions in nongrowing older organisms requires allocation of considerable biological resources, which can pose a large burden for the survival of the whole group or the species. This singular consideration may have been the major driving force for the evolutionary acquisition of the aging process through programmed deterioration of biological functions by postreproductive activation of certain genes $(5,6,10)$.

Strictly from a theoretical standpoint, the genetic program of aging can be operated either by gradually modifying the gene structure (such as chemical modifications of the DNA bases and/or changes in the chromatin structure) or through changes in the level and/or activity of specific gene regulatory proteins, i.e., the transcription factors. Studies on temporal changes in gene expression during the developmental phase of life have established that sequential and progressive changes in the expression of trans-acting proteins play the major role in unfolding the genetic information in an orderly fashion, leading to cellular differentiation and organogenesis (11). Clearly, these processes continue after the birth of the animal to complete the assembly of the reproductive structures during maturation. It is a reasonable corollary that such temporal changes 
in gene expression are extended even beyond the reproductive maturation to influence physiological functions throughout the life span of the organism (1-4).

\section{ROLE OF TRANSCRIPTION FACTORS IN GENE EXPRESSION}

Retrieval of the genetic information from the DNA to RNA by RNA polymerase requires a number of accessory proteins in the form of a multiprotein complex (12). The multimeric "initiation complex" is assembled by sequential attachment of accessory proteins such as the transcription factor IID, transcription factors IIA and IIB, and then RNA polymerase and transcription factor IIF, followed by recruitment of transcription factors IIE, IIH, and IIJ. Assembly of this multiprotein complex occurs at the designated initiation site of specific genes. These sites are either marked with a TATA box or with other alternative recognition elements (13). Efficient transcription of a particular gene not only depends on the proper assembly of the initiation complex, but is also greatly influenced by other sequence-specific regulatory proteins that can bind to designated sites farther away from the site of transcriptional initiation (12). At least one kilobase region upstream of the initiation site is known to harbor most of these cis-elements or transcription factor binding sites. Attachment of these factors upstream of the gene may influence the rate of transcription by a number of incompletely understood mechanisms, including stabilization of the initiation complex, destabilization of the chromatin structure, and conformational change of the promoter domain. In the case of eukaryotic organisms, several hundred of such sequence-specific promoter binding proteins or transcription factors have been identified. Some of the characteristic features of these transcription factors include: (1) amino acid sequences that are conserved across the phylogenetic spectrum; (2) specific DNA binding domains that fall into a small number of characteristic motifs; and, (3) in most cases, dimeric nature of the functional unit. Furthermore, on the basis of common structural motifs, most of the transcription factors can be placed in four large groups, i.e., zinc finger, homeodomain, leucine zipper, and the helix-loop-helix family (14). A newly emerging group that can be considered a fifth family is the $N F-\kappa B / R e l(15)$. In vertebrates, this latter group is comprised of various dimeric combinations of five different monomeric protein subunits which share a highly homologous 300 amino acid-long $\mathrm{N}$-terminal region (called the Rel homology domain). This domain is responsible for dimerization, DNA binding, and nuclear targeting functions. The NF- $\kappa \mathrm{B} / \mathrm{Rel}$ family plays critical roles in regulating the transcription of the genes involved in the mediation of inflammation, oxidative stress, and apoptotic response, all of which may have important bearing on the age-dependent deterioration of organ function.

\section{CHANGES OF TRANSCRIPTION FACTORS IN ORGANISMIC AGING}

In almost all higher forms, with only rare exceptions, the completion of preparatory arrangements for reproductive function marks the beginning of the aging process. Thus, temporal regulation of the transcription factors that mediate some of the key components of the reproductive function can provide important molecular clues to the genetic program of aging. On the basis of this rationale, we have explored the molecular mechanisms of age-dependent regulation of the androgen receptor gene in rat liver which have led to the identification of a number of transcription factors relevant to physiological aging. Hepatic expression of the rat androgen receptor $(r A R)$ gene increases during sexual maturation and declines progressively with aging. The hepatic level of the rAR mRNA in a 20-monthold animal is about 70 -fold lower than that of a 3-month-old young adult (16). The promoter region of the $r A R$ gene has been cloned and characterized both with respect to its transcription factor binding sites and its ability to drive transcription of heterologous fusion genes in transfected cells. About a dozen transcription factors specifically interact with this gene promoter, and at least three appear to be involved in its age-dependent down-regulation (17). These include two positively acting transcription factors, i.e., stimulatory protein-1 (Spl) and the agedependent factor $(\mathrm{ADF})$, and a negative regulator, which is NF- $\kappa \mathrm{B}$.

$\mathrm{Spl}$ is a member of the zinc-finger family of transcription factors and is present in all mammalian cells (18). It activates gene transcription by binding to the "GC-box" (5'-GGGCGGGG-3') motif. Ammendola et al. initially observed a 
marked decline of Spl activity in the brain and liver nuclear extracts of aged rats (19). Although the DNA binding activity of Spl is greatly reduced, immunoblotting experiments show no significant differences in the level of the Spl protein within the nuclear extracts derived from young (4-month-old) and senescent (30-monthold) rats. From these observations, the authors have concluded that the age-dependent decline in $\mathrm{Spl}$ activity is possibly due to protein modification rather than to its decreased synthesis. Spl plays a critical role in the assembly of the TFIID complex at the initiation site of promoters like the $r A R$ gene, which does not contain TATA or CCAAT boxes (17). Because of our interest in the age-dependent regulation of the $r A R$ gene, we also have examined changes in Spl activity during aging and essentially found results similar to those reported earlier by Ammendola et al. $(19,20)$. Spl is a general transcription factor influencing the transcription of a large number of both TATA-less and TATA-containing genes. Thus, such a marked decline in its DNA binding activity can potentially result in a global change in gene transcription and protein synthesis. However, no such age-dependent effect on hepatic protein synthesis has been observed. It is therefore possible that the age-dependent decline of Spl activity may largely be counteracted by the mobilization of other compensatory regulatory mechanisms.

During the characterization of the $r A R$ promoter by DNasel footprinting analysis, we discovered a new cis-element spanning the -311 to -329 base pair positions (16). It binds a novel transcription factor that functions as a positive regulator for the $r A R$ gene. Changes in the hepatic level of this transcription factor correlate with the pattern of the age-dependent expression of the androgen receptor mRNA. We have therefore designated it as the age-dependent factor, or ADF. ADF activity in the rat liver is low before puberty, increases with maturation, and gradually declines during old age. Titration of ADF activity in liver nuclear extracts derived from 3-and 24-month-old rats shows about a 7 -fold decline in its DNA-binding activity. Mutational inactivation of the ADF binding site at the $r A R$ promoter results in about a 4-fold loss of promoter activity in transfected cells. ADF is a ubiquitous transcription factor and the corresponding binding site in two other genes with important roles in development and differentiation has also been established. These include promoters for the retinoic acid receptor $\beta$, and

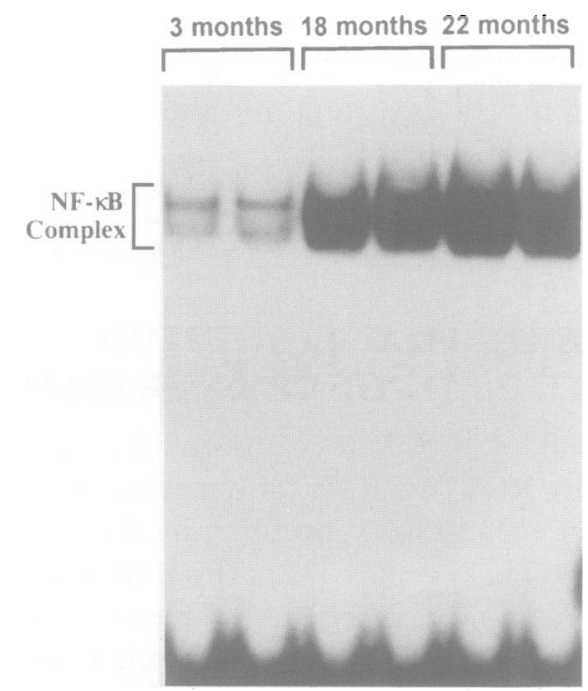

FIG. 1. Age-dependent increase of NF- $\kappa B$ activity in the rat liver

The picture shows results of electrophoretic mobility shift assay of liver nuclear extracts derived from duplicate animals of 3,18 , and 22 months of age. A DNA duplex spanning -574 to -554 base pair positions of the rat androgen receptor gene promoter containing the NF- $\kappa \mathrm{B}$ binding site was used as the radiolabeled probe. (These experiments were performed by Dr. P.C. Supakar in our laboratory.)

adipsin, a protein induced during fibroblast-toadipocyte differentiation. Although both the rat and the mouse androgen receptor promoter contain the ADF binding site, it is precisely excised from the human AR gene promoter. In this context it is interesting to note that unlike rodents, the human liver does not show any major age-dependent difference in androgen receptor gene expression.

The $r A R$ promoter also contains a high-affinity NF- $\kappa \mathrm{B}$ binding site at the -574 to -554 base pair positions that functions as a negative regulatory element. Nuclear activity of NF- $\kappa$ B in the rat liver exhibits a marked age-dependent variation (21). Mutational inactivation of this NF- $\kappa B$ site causes about a 5 -fold increase in promoter activity in the cell transfection assay. As shown in Fig. 1, NF- $\kappa$ B activity in the liver nuclear extract derived from old rats (18 to 22 months) is more than 10 -fold higher than in that of the young adult ( 3 months). Despite such an agedependent increase in NF- $\kappa$ B activity, immunoblot analysis of total hepatic proteins failed to show any corresponding change in the level of either $\mathrm{p} 50$ or $\mathrm{p} 65$ subunits of NF- $\kappa \mathrm{B}$. The latter finding suggests that the increase in nuclear $\mathrm{NF}-\kappa \mathrm{B}$ activity during aging is due to an in- 
creased activation of NF- $\kappa \mathrm{B}$. The NF- $\kappa \mathrm{B}$ proteins are maintained as the functionally inactive cytoplasmic form by virtue of their strong affinity to $\mathrm{I} \kappa \mathrm{B}$, a member of the heat shock family of proteins. When activated by appropriate signals such as $\mathrm{H}_{2} \mathrm{O}_{2}$, I $\kappa \mathrm{B}$ is phosphorylated by an as-yet unidentified protein kinase, resulting in the dissociation of the NF- $\kappa \mathrm{B} / \mathrm{I} \kappa \mathrm{B}$ complex and nuclear translocation of NF- $\kappa \mathrm{B}$. Phosphorylated $\mathrm{I} \kappa \mathrm{B}$ then becomes a target for conjugation with a 76 amino acid-long marker protein called "ubiquitin." Polyubiquitinated proteins are taken up by proteasomes for proteolytic degradation (15). Our observation of a marked increase in the nuclear NF- $\kappa$ B activity in the liver of older rats has implications beyond its negative regulatory function for the $r A R$ gene. Increased oxidative damage and subacute inflammatory response are two of the most important phenotypic changes observed during organismic aging, and activation of NF- $\kappa \mathrm{B}$ provides the signaling mechanism for both the oxidative stress and inflammatory response (22). In addition to liver, age-dependent increase in NF- $\kappa$ B activity has also been observed in other tissues such as heart, brain, and kidney (23).

The heat shock family of proteins (HSPs) are inducible both by thermal and oxidative stress (24). Some members of this family are involved in the regulation of normal physiological functions, such as (1) correct folding of nascent peptides during mRNA translation, (2) sequestering of denatured proteins, and (3) transport of regulatory proteins into the nucleus (25-27). Both steroid receptors and NF- $\kappa \mathrm{B}$ are kept in inactive cytoplasmic forms by complexing with specific members of the HSP family of proteins. When rats are subjected to thermal stress, the induction of the mRNA for one of the major heat shock proteins, HSP-70, shows a marked age-associated decrease in a number of tissues, including brain, lung, and skin (28). An age-dependent decline in the induction of HSP-70 mRNA has also been observed in the fruit fly and in hepatocytes derived from young and old rats, and in mononuclear leukocytes obtained from young and old human subjects (29-31). The rate of transcription of a subset of heat shock protein genes is specifically influenced by a transcription factor called "heat shock factor 1" (HSF-1). This factor binds to sequence elements containing inverted repeats of NGAAN (heat shock element or HSE) (32). In addition to HSP, HSE is found in a number of other gene promoters, including the metallothionein genes. Metallothioneins are a group of small cysteine-rich, metal-binding proteins (33).
Because metal ions such as $\mathrm{Fe}^{2+}$ and $\mathrm{Cu}^{2+}$ catalyze Fenton and Haber-Weiss reactions that generate hydroxyl and oxygen free radicals ( $\mathrm{OH}$ and $\mathrm{O}_{2^{-}}{ }^{-}$), metallothioneins can also function as intracellular antioxidants (34). Thus, an agedependent decline of HSF-1 may reduce the cellular level of metallothioneins and add to the overall oxidative stress. Although the nuclear level of sequence-specific DNA binding activity of HSF- 1 is markedly reduced during old age, immunoblot analysis shows that the immunoreactive HSF-1 protein does not change with age $(35,36)$. Again, this situation is very similar to that found in $\mathrm{Spl}$ and NF- $\kappa \mathrm{B}$, suggesting an age-dependent impairment of HSF-l activity rather than its synthesis.

\section{TRANSCRIPTION FACTORS AND CELLULAR SENESCENCE}

Differentiated cells derived from newborn animals, when maintained continuously in vitro, stop dividing after a certain number of population doublings. This phenomenon was originally established with human embryonic lung fibroblasts and is generally referred to as replicative senescence or cellular senescence (37). Besides fibroblasts, replicative senescence has been reproduced with a number of other cell types. Because cells derived from older individuals and animals with shorter life-span potential undergo replicative senescence after a smaller number of population doublings in vitro $(38,39)$, cellular senescence has been used as an experimental model to study the molecular aspects of physiological aging (40). However, it needs to be emphasized that organismic aging involves additional factors that may not be reflected in cellular senescence, and that some of the factors contributing to mitostasis under in vitro culture conditions may not be relevant to organismic aging (41). Furthermore, physiological aging manifests itself in both dividing and nondividing cells. Despite these limitations, results obtained through studies of cellular senescence can complement those derived from organismic aging; these results are summarized below.

High levels of the transcription factor called "activator protein-1" (AP-1) are required to turn on a number of genes that serve as gate-keepers for quiescent cells before they are propelled into 
the cell cycle by the mitogenic stimuli (42). AP-1 is a dimeric transcription factor composed of two protein subunits, c-Fos and c-Jun. In senescent cells, both c-Fos protein and its corresponding mRNA are almost undetectable (43). Additionally, unlike the quiescent cells, c-Fos cannot be induced by the mitogenic constituents of blood serum. The effect of serum on cell division is mediated by the activation of several growth stimulatory transcription factors that contain serum response elements (SREs) in their gene promoters. The SREs at the promoter region bind a transcription factor called "serum response factor" (SRF). In senescent cells, SRF is present in a hyperphosphorylated form with markedly reduced DNA-binding affinity (44). Thus, hyperphosphorylation of SRF in senescent cells may contribute to mitostasis. However, it has also been reported that senescent fibroblasts derived from patients with Werner's syndrome (an accelerated aging syndrome, where fibroblasts undergo premature replicative senescence) can be induced to proliferate after serum treatment with increased synthesis of c-Fos (45).

Cellular senescence is also associated with the loss of another heterodimeric transcription factor called "E2F" which is needed for transcription of several genes that are induced immediately before the $S$ phase of the cell cycle (46). One of these genes codes for the enzyme, dihydrofolate reductase, which is an essential enzyme for DNA synthesis (47). Another critical enzyme for DNA synthesis is thymidine kinase (TK), which is down-regulated 5- to 7-fold during cellular senescence. The TK gene promoter contains a CCAAT motif that specifically binds to a transcription factor called "CBP/tk." The nuclear level of $\mathrm{CBP} / \mathrm{tk}$ is greatly reduced in senescent human fibroblasts, possibly because of its high susceptibility to oxidative damage (48).

Finally, overexpression of a mitogenic inhibitory protein called "p21" appears to play an important role in the development of mitostasis associated with cellular senescence (49). p21 acts as an inhibitor of the cyclin-dependent protein kinase (Cdk2) which phosphorylates and thereby activates the retinoblastoma protein, $\mathrm{Rb}$. Hypophosphorylated $\mathrm{Rb}$ inhibits the transcription factor $\mathrm{E} 2 \mathrm{~F}$ by sequestering it into an inactive form, and, as described before, E2F is essential for the activation of a number of genes that are involved in propeling the cell from the Gl to the $S$ phase of the cell cycle.

\section{PERSPECTIVES AND SPECULATIONS}

In this review I have underscored the point that the age-dependent impairment of physiological functions begins to be observed only after sexual maturation. In semelparous animals (which, like the Pacific salmon, breed only once), it happens in an abrupt fashion with an accelerated rate of aging, while for most other iteroparous species (animals that can reproduce repeatedly) it is a rather gradual process (50). With all other conditions remaining unaltered, differences in pre- and postreproductive organ function can be attributed to two biochemical pathways: (1) impairment of certain critical repair processes, and (2) activation of specific destructive signals. Results derived from a number of model systems, involving such diverse life-forms as animals, plants, and fungi, suggest that both of these pathways may be used to promote aging, albeit to different degrees $(3,50,51)$. Although the impairment of repair functions and the activation of destructive signals can be mediated by temporally programmed changes in specific gene expression, the signaling cascade also involves protein modification.

Oxidation (52,53), glycation (54), and phosphorylation and dephosphorylation (55) are some of the chemical and enzymatic processes that alter protein structures and may change their biological activity during aging. Among these processes, oxidative damage is the predominant cause of the age-dependent decline of biological functions. Stadtman and colleagues have reported that the cellular levels of nonfunctional oxidized proteins progressively increase with age. Both in experimental animals and in the human, $40-50 \%$ of the total cellular proteins in the elderly are found in oxidized and possibly nonfunctional forms (52). It should also be noted that all proteins are not equally susceptible to oxidative damage. Proteins that are most sensitive to redox changes may be uniquely suited to serve as signaling agents in the signal transduction pathways leading to either activation or inactivation of trans-acting factors $(22,56,57)$.

The age-associated accumulation of oxidized proteins occurs both in tissues that do (e.g., dermal fibroblasts) and do not (e.g., neurons) undergo cell renewal (52). Furthermore, changes in intracellular protein degradation have not been observed in all tissues examined so far (53). Thus, the critical role of a gradual increase in the rate of oxidative damage during aging deserves a 


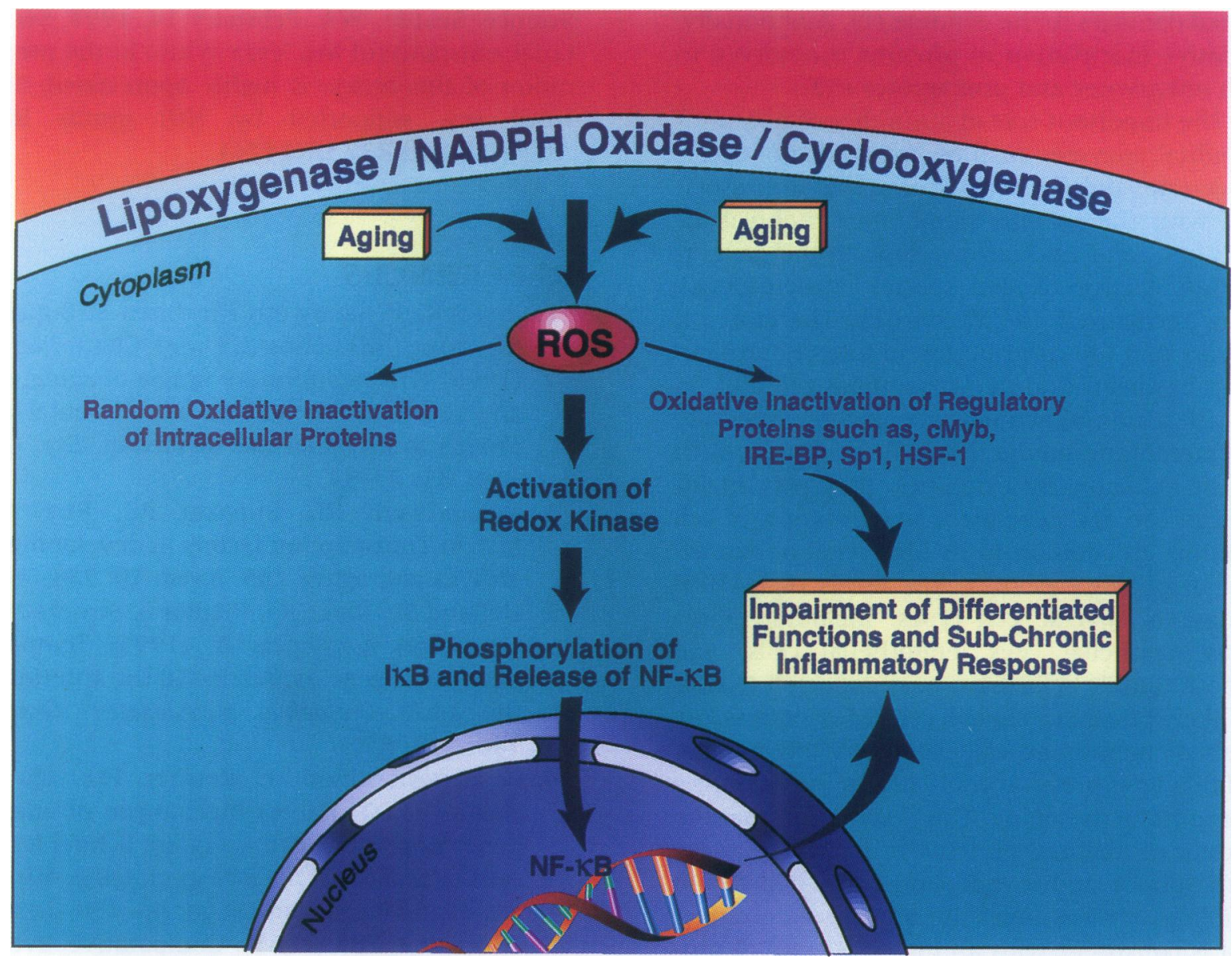

FIG. 2. A model for programmed increase in reactive oxygen species and altered transcription factor function during aging

The model postulates that the cellular level of reactive oxygen species (ROS) gradually rises because of corresponding increases in membrane-associated oxidative enzymes such as NADPH oxidase, lipoxygenase, and cyclooxygenase. Intracellular rise in ROS can then activate NF- $\kappa$ B and initiate a subchronic inflammatory response. Furthermore, besides causing random oxidative damage to intracellular proteins, ROS can preferentially inactivate certain redox sensitive trans-acting factors such as cMyb (65), IRE-BP (iron response element binding protein) (66), Spl (19), and HSF-1 $(35,36)$, with deleterious consequences to cell function. Although for the sake of simplicity, lipoxygenase/NADPH oxidase/cyclooxygenase are all depicted together, these enzymes have been localized in the following membrane fractions: lipoxygenase, plasma membrane, and nuclear membrane (59); NADPH oxidase, plasma membrane (61); cyclooxygenase, endoplasmic reticulum, and nuclear membrane (60).

serious consideration. Oxidative damage to proteins, nucleic acids, and lipids is mediated by reactive oxygen species (ROS), which include hydrogen peroxide $\left(\mathrm{H}_{2} \mathrm{O}_{2}\right)$, oxygen free radical $\left(\mathrm{O}_{2^{-}}{ }^{-}\right)$, hydroxyl free radical $\left({ }^{\circ} \mathrm{OH}\right)$, singlet oxygen $\left({ }^{1} \mathrm{O}_{2}\right)$, hypochlorite anion $\left(\mathrm{OCl}^{-}\right)$, and the peroxynitrite anion, $\left(\mathrm{ONOO}^{-}\right)$. The latter two are formed by the interaction between $\mathrm{Cl}^{-}$and $\mathrm{H}_{2} \mathrm{O}_{2}$, and nitric oxide (NO) and $\mathrm{O}_{2^{-}}$, respectively. Most of these ROS are interconvertible, and they are produced not only as accidental escapees from the mitochondrial and peroxisomal oxidative processes, but some of them are also enzymatically produced in other parts of the cell to serve as signaling agents $(56,57)$. The mitochondrially produced ROS have thus far been considered the major cause of oxidative damage and biological aging (53). However, the evolution of aging may have preceded the acquisition of the prokaryotic mitochondrion as an endosymbiont of the eukaryotic cell. More than a thousand species of present-day protozoa and fungi lack mitochondria (58). Many of these amitochondrial eukaryotes also follow a sexual mode of reproduction and undergo meiotic division, adaptations developed to counteract age- 
related damages to the genome (1). Additionally, oxidative inactivation of proteins is observed in both eukaryotes and prokaryotes (52).

The important role of a number of nonmitochondrial enzymes such as lipoxygenase, cyclooxygenase, and NADPH oxidase that are associated with the plasma membrane, endoplasmic reticulum, and nuclear envelope in the generation of reactive oxygen species is increasingly being recognized $(56,57,59-61)$. Therefore, it appears that the contribution of mitochondria in aging has been unduly overemphasized and, in fact, these nonmitochondrial enzymes, especially the membrane-bound NADPH oxidase, which can be activated by cytokines, may play major roles in the age-dependent deterioration of cell function. In addition to its high level of expression in phagocytes (62), low levels of NADPH oxidase in diverse cell types, including fibroblasts, epithelial cells, endothelial cells, and smooth muscle cells, have been reported (63). It is a likely possibility that all cell types express low levels of membrane-associated NADPH oxidase and that its expression gradually increases during postreproductive aging. The observation that the amount of oxidized proteins varies with the age of the donor and is independent of population doublings (at least over the intermediate range) (64) is consistent with an increased rate of protein oxidation during organismic aging. Furthermore, the increase in chronic inflammatory responses, as observed with physiological aging, could also be due to the increased rate of ROS production by nonmitochondrial enzymes such as the membrane-associated NADPH oxidase. Although subsequent steps in the transmission of the redox signal can occur through multiple pathways, activation of NF- $\kappa$ B appears to be the major route. Figure 2 outlines this hypothesis and, if it is proven to be correct, then it will be possible to slow down the rate of aging and delay the onset of age-dependent dysfunctions by pharmacological intervention with anti-inflammatory agents.

\section{ACKNOWLEDGMENTS}

I thank Drs. B. Chatterjee and Y. Lavrovsky for helpful discussions. I would also like to acknowledge the contributions of my present and former colleagues whose names are cited in the references. This minireview is partly based on a lecture presented at the Annual Meeting of the American Association for the Advancement of
Science, Seattle, WA, February 14, 1997. Secretarial assistance of Ms. Nyra White in the preparation of this article is highly appreciated. This work was supported by NIH grants RO1 AG10486 and R37 DK14744.

\section{REFERENCES}

1. Roy AK, Vellanoweth RL, Chen S, Supakar PC, Jung MH, Song CS and Chatterjee B. (1996) The evolutionary tangle of aging, sex and reproduction and an experimental approach to its molecular dissection. Exp. Gerontol. 31: 83-94.

2. Vellanoweth RL, Supakar PC, Roy AK. (1994) Transcription factors in development, growth and aging. Lab. Invest. 70: 784-799.

3. Helfand SL, Blake KJ, Rogina B, Strocks MD, Centurion A, Naptra B. (1995) Temporal patterns of gene expression in the antenna of the adult Drosophila melanogaster. Genetics 140: 549-555.

4. Papaconstantinou J, Reisner PD, Liu L, Kuninger DT. (1996) Mechanism of altered gene expression with aging. In: Schneider EL (ed). Handbook of the Biology of Aging, 4th ed. Academic Press, San Diego, pp. 150-183.

5. Kirkwood TB. (1985) Comparative evolutionary aspects of longevity. In: Finch CE, Schneider EL (eds). Handbook of the Biology of Aging, 2nd ed. Van Nostrand, New York, pp. 27-44.

6. Partridge L, Barton NH. (1993) Optimality, mutation and the evolution of ageing. Nature 362: 305-311.

7. Demple B. (1966) Redox signalling and gene control in the Escherichia coli soxRS oxidative regulon-a review. Gene 179: 53-57.

8. Wyllie AH. (1994) Apoptosis: Death gets a brake. Nature 369: 272-273.

9. Wilson EO. (1971) The Insect Societies. Belknap Press, Cambridge, MA.

10. Rose MR. (1991) Evolutionary Biology of Aging. Oxford University Press, New York.

11. Nothias JY, Majumdar S, Kaneko KJ, Depansphilis ML. (1995) Regulation of gene expression at the beginning of mammalian development. J. Biol. Chem. 270: 2207722080.

12. Pugh BF, Tjian R. (1992) Diverse transcriptional functions of the multisubunit eukaryotic TFIID complex. J. Biol. Chem. 267: 679682.

13. Azizkhan JC, Jensen DE, Pierce AF, Wade 
M. (1993) Transcription from TATA-less promoters: Dihydrofolate reductase as a model. Crit. Rev. Eukaryot. Gene Expr. 3: 229254.

14. Sauer RT, Pabo CO. (1992) Transcription factors: Structural families and principles of DNA recognition. Annu. Rev. Biochem. 61: 1053-1095.

15. Baeuerle PA, Baltimore D. (1996) NF- $\kappa$ B: Ten years after. Cell 87: 13-20.

16. Supakar PC, Song CS, Jung MH, Slomczynska MA, Kim J-M, Vellanoweth RL, Chatterjee B, Roy AK. (1993) A novel regulatory element associated with age-dependent expression of the rat androgen receptor gene. J. Biol. Chem. 268: 26400-26408.

17. Roy AK, Chatterjee B. (1995) Androgen action. Crit. Rev. Eukaryot. Gene Expr. 5: 157176.

18. Kadanoga JT, Carner K, Masiarz FR, Tjian R. (1987) Isolation of cDNA encoding transcription factor $\mathrm{Spl}$ and functional analysis of the DNA binding domain. Cell 51: 10791090.

19. Ammendola $R$, Mesuraca $M$, Russo $T$, Cimino F. (1992) Spl DNA binding efficiency is highly reduced in nuclear extracts from aged rat tissues. J. Biol. Chem. 267: 17944-17948.

20. Supakar PC, Roy AK. (1996) Role of transcription factors in the age-dependent regulation of the androgen receptor gene in rat liver. Biol. Signals 5: 170-179.

21. Supakar PC, Jung MH, Song CS, Chatterjee $B$, Roy AK. (1995) Nuclear factor $\kappa$ B functions as a negative regulator for the rat androgen receptor gene and NF- $\kappa$ B activity increases during age-dependent desensitization of the liver. J. Biol. Chem. 270: 837842.

22. Schreck R, Baeuerle PA. (1991) A role of oxygen radicals as second messengers. Trends Cell Biol. 1: 39-42.

23. Helenius $M$, Hanninen $M$, Lehtinen SK, Salminen A. (1996) Aging-induced upregulation of nuclear binding activities of oxidative stress responsive NF- $\kappa \mathrm{B}$ transcription factor in mouse cardiac muscle. J. Mol. Cell Cardiol. 28: 487-498.

24. Morimoto RI. (1993) Cells in stress: Transcriptional activation of heat shock genes. Science 259: 1409-1410.

25. Gething MJ, Sambrook J. (1992) Protein folding in the cell. Nature 355: 33-45.

26. Hendrick JP, Hartl FU. (1993) Molecular chaperone functions of heat shock proteins. Annu. Rev. Biochem. 62: 349-384.

27. Pratt WB. (1993) The role of heat shock proteins in regulating the function, folding and trafficking of the glucocorticoid receptor. J. Biol. Chem. 268: 21455-21458.

28. Blake MJ, Fargnoli J, Gershon D, Holbrook NJ. (1991) Concomitant decline in heat induced hyperthermia and HSP 70 mRNA expression in aged rats. Am. J. Physiol. 260: R663-R667.

29. Niedzwiecki A, Kongpachith AM, Fleming JE. (1991) Aging affects expression of 70kDa heat shock proteins in Drosophila. J. Biol. Chem. 266: 9332-9338.

30. Heydari AR, Wu B, Takahashi R, Strong R, Richardson A. (1993) Expression of heat shock protein $\mathbf{7 0}$ is altered by age and diet at the level of transcription. Mol. Cell Biol. 13: 2909-2918.

31. Deguchi Y, Negoro S, Kishimato S. (1988) Age-related changes of heat shock protein gene transcription in human peripheral blood mononuclear cells. Biochem. Biophys. Res. Commun. 157: 580-584.

32. Rabindran SK, Giorgi G, Cloo J, Wu C. (1991) Molecular cloning and expression of a human heat shock factor HSF1. Proc. Natl. Acad. Sci. USA 88: 6906-6910.

33. Kagi JHR. (1991) Overview of metallothionein. Methods Enzymol. 205: 613-626.

34. Liu XD, Thiele DJ. (1997) Yeast metallothionein gene expression in response to metals and oxidative stress. Methods 11: 289-299.

35. Lee YK, Manalo D, Liu AYC. (1996) Heat shock response, heat shock transcription factor and cell aging. Biol. Signals 5: 180-191.

36. Fawcett TW, Sylvester SL, Sarge KD, Morimoto RI, Holbrook NJ. (1994) Effects of neurohormonal stress and aging on the activation of mammalian heat shock factor 1 . J. Biol. Chem. 269: 32272-32278.

37. Hayflick L. (1965) The limited in vitro lifespan of human diploid cell strains. Exp. Cell Res. 37: 614-636.

38. Martin GM, Sprague CA, Epstein CJ. (1970) Replicative lifespan of cultivated human cells: Effects of donor's age, tissue and genotype. Lab. Invest. 23: 86-92.

39. Goldstein S. (1974) Aging in vitro: Growth of cultured cells from Galapagos tortoise. Exp. Cell Res. 83: 297-302.

40. Meyyappan M, Atadja PW, Riabowol KT. (1996) Regulation of gene expression and 
transcription factor binding activity during cellular aging. Biol. Signals 5: 130-138.

41. Loo DT, Fuquay JI, Rawson CL, Barnes DW. (1987) Extended culture of mouse embryo cells without senescence: Inhibition by serum. Science 236: 200-202.

42. Angel P, Karin M. (1991) The role of Jun, Fos and the AP-1 complex in cell proliferation and transformation. Biochim. Biophys. Acta. 1072: 129-157.

43. Seshadri T, Campisi J. (1990) Repression of c-fos transcription and altered genetic program in senescent human fibroblasts. Science 247: 205-209.

44. Atadja PW, Stringer KF, Riabowol KT. (1994) Loss of serum response elementbinding activity and hyperphosphorylation of serum response factor during cellular aging. Mol. Cell. Biol. 14: 4991-4999.

45. Oshima J, Campisi J, Tannock CA, Martin GM. (1995) Regulation of c-fos in senescing Werner's syndrome fibroblasts differs from that observed in senescing fibroblasts from normal donors. J. Cell. Physiol. 162: 277-283.

46. LaThangue NB. (1994) DP and E2F proteins: Components of a heterodimeric transcription factor implicated in cell cycle control. Curr. Opin. Cell. Biol. 6: 443-450.

47. Good LF, Dimri GP, Campisi J, Chen KY. (1996) Regulation of dihydrofolate reductase gene expression and E2F components in human diploid fibroblasts during growth and senescence. J. Cell. Physiol. 168: 580-588.

48. Pang JH, Chen KY. (1993) A specific CCAAT-binding protein, $\mathrm{CBP} /$ tk may be involved in the regulation of thymidine kinase gene expression in human IMR-90 diploid fibroblasts during senescence. J. Biol. Chem. 268: 2909-2916.

49. Smith JR, Pereira-Smith OM. (1996) Replicative senescence: Implications for in vivo aging and tumor suppression. Science 273: 63-67.

50. Finch CE. (1990) Longevity, Senescence and the Genome. Chicago University Press, Chicago.

51. Jazwinski M. (1996) Longevity, genes, and aging. Science 273: 54-59.

52. Stadtman ER. (1992) Protein oxidation and aging. Science 257: 1220-1224.

53. Sohal RS, Weindruck R. (1996) Oxidative stress, caloric restriction, and aging. Science 273: $59-63$.
54. Cerami A, Vlassara H, Brownlee M. (1987) Glucose and aging. Sci. Am. 256: 90-96.

55. Hunter T, Karin M. (1992) The regulation of transcription by phosphorylation. Cell 70: 375-389.

56. Khan AU, Wilson T. (1995) Reactive oxygen species as cellular messengers. Chem. Biol. 2: 437-445.

57. Muller JM, Rupec RA, Baeuerle PA. (1997) Study of gene regulation by NF- $\kappa$ B and AP- 1 in response to reactive oxygen intermediates. Methods 11: 301-312.

58. Cavalier-Smith T. (1987) Eukaryotes with no mitochondria. Nature 326: 332-333.

59. Hagmann W, Gao X, Timar J, Chen YQ, Strohmaier AR, Fahrenkopf C, Kagawa D, Lee M, Zacharek A, Honn K. (1996) 12-Lipoxygenase in A431 cells: Genetic identity, modulation of expression, and intracellular localization. Exp. Cell Res. 228: 197-205.

60. Smith WL, Garavito RM, DeWitt DL. (1966) Prostaglandin endoperoxidase $\mathrm{H}$ synthases (Cyclooxygenases)-1 and 2. J. Biol. Chem. 271: 33157-33160.

61. Park JW, Hoyal CR, Benna JE, Babior BM. (1997) Kinase-dependent activation of the leukocyte NADPH oxidase in a cell-free system. Phosphorylation of membranes and p47 (phox) during oxidase activation. J. Biol. Chem. 272: 11035-1 1043.

62. Rossi P. (1986) The $\mathrm{O}_{2}{ }^{-}$-forming $\mathrm{NADPH}$ oxidase of the phagocytes: Nature, mechanism of activation and function. Biochim. Biophys. Acta. 853: 65-89.

63. Meier B, Cross AR, Hancock JT, Kaup FJ, Jones OTG. (1991) Identification of a superoxide-generating NADPH oxidase system in human fibroblasts. Biochem. J. 275: 241-245.

64. Oliver CN, Ahn BW, Moerman EJ, Goldstein S, Stadtman ER. (1987) Age-related changes in oxidized proteins. J. Biol. Chem. 262: 5488-5491.

65. Guehman S, Vorbruggen G, Kalkbrenner F, Moelling K. (1992) Reduction of a conserved Cys is essential for Myb DNA-binding. Nucl. Acids Res. 20: 2279-2286.

66. Hentze MW, Ronault TA, Harford JB, Klausner RD. (1989) Oxidation-reduction and the molecular mechanism of a regulatory RNAprotein interaction. Science 244: 357-359. 